
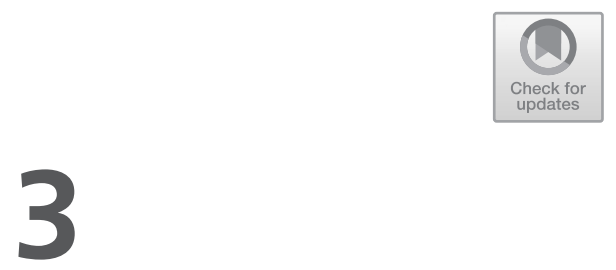

\title{
The Family Assessment Interview: The Narrative, Formulation, and Discussion of Treatment Options
}

\begin{abstract}
The clinical encounter with the mental health clinicianor multidisciplinary team - typically begins in the family assessment interview, where engagement and rapport building between the clinician and the family take place through a series of therapeutic processes. First comes the process of generating a narrative. The child or adolescent and family present, roughly chronologically, the family genogram (which gives a bird's-eye view of the family story across three generations), the child's developmental history, and the story of the child's symptoms. This process provides the clinician with key information: the story of the family's adverse experiences and those of the child (ACEs); how the family and child managed such experiences; and a working understanding of the factors that have shaped the child's stress system. This therapeutic conversation also provides the child and family with the experience of being listened to and heard. Second comes the process of co-constructing a formulation: the narrative told by the child and family is framed through the lens of the stress-system model. Thus
\end{abstract}

Electronic supplementary material The online version of this chapter (https://doi.org/10.1007/978-3-030-46184-3_3) contains supplementary material, which is available to authorized users. 
interpreted within the neurobiology of brain, body, and mind, the child's symptoms take on new meaning. They come to be understood by the child and family as reflecting activation or dysregulation of the stress system in response to physical and psychological stress. Third come the discussion and rationale regarding the mind-body interventions that are needed to target the identified areas of dysfunction. Fourth comes the therapeutic contract. Once the family interview has been completedand rapport and a shared understanding of the problem have been established-the clinician and family are in a good position to work together as a team to enable the child to get back on the road to health.

\section{The Family Assessment Interview}

For the mental health clinician, the family assessment interview is usually the first encounter with the child (including the adolescent) presenting with functional somatic symptoms and with her family (Kozlowska et al. 2013). Some children and families will come to the assessment in the wake of a positive experience within the health care system. They will have seen a doctor or paediatrician who completed the medical assessment with skill and empathy, and who, in a timely manner, provided the child and family with a clear diagnosis and explanation. In this scenario, the paediatrician has already created a secure base from which the child, family, and mental health clinician can feel safe enough to explore the various factors that contributed to the child's presentation (see Chapter 2 ). These families will come to the family interview with an open stance keen to do whatever is necessary to help the child get better.

Other children and families will come to the assessment in the wake of a negative experience within the health care system (see the vignette of Samantha in Chapter 2). They will have seen a doctor or paediatrician who did not understand functional somatic symptoms, who was irritated by them, or who felt too anxious to give a positive diagnosis and talked only about the diagnoses that the child did not have (diagnoses of exclusion). Alternatively, the child and family may have experienced throwaway remarks made by an ambulance driver, nurse, or accident and emergency doctor who perceived the symptoms as not being 
part of 'real medicine' (see the vignette of Samantha in Chapter 2). In this scenario, the child and family may have been knocked about in the medical system and may bring with them memories of negative interactions with health care providers, as well as experiences of feeling unheard, dismissed, or even derogated (see Text Box 3.1). They will come to the family interview with a defensive stance, ready to defend the child or themselves from further put-downs. The secure base from which the child, family, and mental health clinician can feel safe enough to explore the various factors that contributed to the child's presentation has yet to be established.

\section{Text Box 3.1. Examples of derogatory comments made by health care workers-Reported by families to the first and third authors' clinical teams, or reported in the literature}

'They are false seizures'

'She's faking it'

'Stop looking for attention'

'She is just making it up for attention'

'Attention seeker'

'Drama queen'

'Putting on episodes'

'Hypochondriac'

'Leave her at home on the bed and let her have it [the episode]'

'The problem is supratentorial'

'It's all in the head'

'He's doing his dying-swan act again'

'I know you're are faking it; snap out of It'

'Life is a bucket of shit; put a lid on it'

'Wanting attention from mummy and daddy'

'Waste of government time and funding'

'I am grabbing my coworker and walking out'

'To save her [the patient] the embarrassment, I will take her [in the ambulance]'

'Time wasters' (Worsely et al. 2011)

'Fakers' (Worsely et al. 2011)

'Should be shot' (Worsely et al. 2011)

To make things more complicated, the family may find the family assessment interview challenging for other reasons. The interviewer may 
touch upon events that the family would prefer to leave in the past. The interviewer may see temporal connections between events in the family story and patterns of response in the child's body-phenomena that may have, to date, been uncoupled and that, in some cases, the family would prefer to remain that way. Connecting the story of the child's body to the story of the challenges and adversities in her life can be difficult and emotionally painful. Because families differ in their inherent capacities and preparedness to manage the interview process and to make connections between the family story and the story of the child's body, the process of generating a narrative-and engaging with the familymay be straightforward, fraught with difficulty, or anywhere in between.

In this context, establishing rapport - the therapeutic relationshipand a secure base with the child and family should be considered the primary goals of the family assessment interview. The clinician (or in some settings, the multidisciplinary team) needs to engage the child and family, and to connect with them in a constructive way that looks to the future. While the first interview with the child and family can be set up and run in many different ways - the way we run the interview being just one possible way (Kozlowska et al. 2013) — the sections below highlight some key elements. The overarching goal is to increase the probability that the assessment process will set the stage for the child, family, and clinician to work together with 'mutual confidence, respect and acceptance' (Sattler 1992, p. 404). For a discussion of different assessment formats, see Online Supplement 3.1.

\section{When Repair Is Needed}

When the family steps into the clinic room, the clinician can make no assumptions about the family's experience through the health care system. To highlight just how difficult the situation might be, we pick up the story of Samantha (see Chapter 2). In the normal course of events, any repair pertaining to adverse experiences in the health care system takes place as part of the normal assessment process (see following sections). Samantha's story highlights how the repair process may need to take priority and may need to be dealt with upfront. 
Samantha entered the clinic room with her father, younger brother, and paternal grandparents (who lived with the family). They were glaring at the clinician - and other members of the multidisciplinary team-with hostility, and Samantha's father stated outright, 'There is nothing wrong with our family, and we won't be answering any of your stupid questions.' It was clear from the outset that the family were hurt and angry, and that the assessment interview could not proceed in the usual manner. In this context, the clinician made a statement acknowledging that many families whose child was seeking treatment for non-epileptic seizures (NES) had reported horrendous experiences in the medical system. She invited Samantha and her family to tell her what had happened to them.

Samantha wept with anger as she recounted how different professionals had treated her. The ambulance officer had sternly told her, 'Stop it! I know you're putting it on.' The emergency department doctor had taken her father aside and told him that 'Samantha is faking it.' A nurse had told Samantha that life was a 'bucket of shit' and that she should 'put a lid on it'. The paediatrician who examined her concluded that the seizures - he called them pseudoseizures and said they were psychogenicfunctioned as a means of avoiding school. Samantha's impression was that the paediatrician thought she was not quite right in the head. When the family was subsequently interviewed by the local mental health service, they were grilled in an effort to elicit a history of sexual abuse.

The clinician (and team) listened to the above story-calmly, patiently, and with no effort to hurry it or avoid the unpleasant details. Gravely, and with sadness, the clinician told the family that most medical and paramedical staff knew little or nothing about NES because this area of medicine had been largely neglected. The clinician then explained that the word pseudoseizure referred to the fact that NES could look just epileptic seizures but that on the electroencephalogram (EEG) they did not have the signature spike pattern of epilepsy. So, the word pseudo did not mean fake. It just meant not epileptic. The clinician also explained that the word psychogenic was still used by some neurologists and others becausein the past - it had been thought that NES were psychological in origin. But now we know better. NES are caused by stress on the body and brain. The stress could be physical (e.g., an illness or pain) or psychological (e.g., bullying at school, stress in relationships, or painful or stressful memories about past events). For this reason NES have also been referred to as stress seizures. They were very common, and the team saw a new patient with NES every one or two weeks. 
Now, Samantha and her family were listening.

The clinician also told Samantha that the words malingering and factitious, referred to people who were putting it on. But neither of these words applied to Samantha. Her diagnosis was NES and chronic/complex pain.

At this point in the interview, an hour had passed, and the clinician decided to offer the family a formulation based on the information that the family had offered on their own, without being directly asked. The clinician began the formulation from the most biological factor that she could identify since the family had expressively communicated that they found discussion of family issues difficult. The clinician said that from what the family had told her, it seemed that several biological factors were contributing to Samantha's NES. First, Samantha had reached puberty, and it was well known that female sex hormones increased risk for NES. In all available studies, females have been more prone than males to develop NES. The reason is that female stress hormones up-regulate the stress system, which is made up of the various brain-body systems that activate in response to stress.

Second, the clinician had noticed that Samantha had been breathing very fast during the assessment, at 28 breaths or more per minute. The clinician said that some kids hyperventilated when their stress systems were switched on. She explained that in a study that the team had completed, 50 percent of the children with NES triggered their symptoms with hyperventilation. The family told the clinician that they had also noticed that Samantha hyperventilated. The grandfather said that he was always telling her to calm herself down.

Third, the clinician - a doctor-asked Samantha if it was OK if she felt her neck and back for any tension patterns. This examination elicited significant discomfort and identification of trigger points in the muscles of the neck and shoulder region (for references see Online Supplement 1.3). Everyone could see Samantha's response to the palpation of her tense muscles. The clinician told Samantha and the family that chronic tension in the muscles of the head and neck contributed to chronic headache and needed to be addressed if Samantha's headache was to get better.

Fourth, Samantha had been suffering from chronic pain. The clinician noted that pain can also up-regulate the brain-body stress systems and contribute to NES. The family nodded and said that Samantha had been in a lot of pain and that they had noticed that the pain made her distressed.

At this point in the interview the family volunteered yet another stress. They said that the Samantha had been very traumatized by her mother's 
violent outbursts and that memories of that trauma continued to play on her mind. When these memories were triggered, Samantha was unable to sleep, and the family thought that this lack of sleep could also be contributing to her NES.

The clinician confirmed that both the trauma-related memories and the lack of sleep functioned to up-regulate the brain-body stress systems, making Samantha even more prone to NES.

The team then offered the family either a place in the inpatient Mind-Body Program or, if they preferred, outpatient therapy in their local community (in which case the Mind-Body Program could serve as a backup). Samantha was relieved that the NES could be treated. The family chose the outpatient option. The team did a careful handover of the case, and Samantha-after some hard work with her psychologist-returned to health and well-being.

\section{The Narrative: Building a Therapeutic Relationship via the Storytelling Process}

In the normal course of events-when the usual interview structure can be used-the therapeutic relationship can be built via the storytelling process. For the first author $(\mathrm{KK})$ and her team, the storytelling process begins with the construction of the family genogram. The genogram gives a bird's-eye view of the family story across three generations. It identifies the family medical history, mental health history, and key family events, including births, deaths, separations, feuds, illnesses, and hospitalizations, along with their impact on the child. As the interview progresses, it is the clinician's job to make sure that key family events that were identified in the genogram are woven into the fabric of the narrative. The genogram brings into focus-through visual representation-key points in the family story that may need to be further discussed (McGoldrick et al. 2008). For example, if the genogram shows that the child's parents separated when the child was five, then-when the story reaches age five, and if the family fails to mention the separation-the interviewer needs to ask a question about the separation and its impact on the child and family. 
Once the genogram is complete, the clinician conducting the interview asks the family to tell the story of the child's development and her symptoms. The clinician tracks the child's story in temporal order, starting with a brief account-usually from the child's mother-of the child's early developmental history, starting from conception. Was the child a planned child? How was the pregnancy? Was the family generally doing well, or was it, for example, conflicted, disrupted, or unsettled, during the pregnancy? Did the delivery go well? Did self-regulation milestones-feeding, sleeping, settling, connecting with others-go well in the first year of life? Were other milestones normal? Was the family doing well also? Did the child have any separation anxiety as a preschooler? What was she like in the preschool years? Did she make friends? Were there any family events or health issues? And so on, and so on. In the normal course of events, the family will take over the telling of the story, with the interviewer asking the odd question, to help the family think about the manner in which the child and her body responded to family events.

As the story moves into the school years, the clinician involves the child — and siblings — in the storytelling process more and more. From the time that the child attended preschool or kindergarten, the clinician tracks the story by school years to scaffold the child's memory and to anchor life events in the context of school years marked by specific teachers, classes, or classroom friends. At some point, the story merges into the story of the child's functional somatic symptoms. Throughout the storytelling process, the clinician maintains the story's temporal order-'put that on hold, we haven't gotten to year 5 yet'-and encourages the child to tell as much of the story as possible. Along the way, the clinician obtains additional details about the symptoms and asks questions that connect the symptoms to the context in which they occurred-to the year at school, to any important events at school, at home, or in the broader family or social context, and to the family's experience with the medical system. The questions help the familywhile they are telling their story-to make connections between the child's symptoms and context.

The storytelling process has a number of important functions. First, the family need to know that their concerns have been heard and that 
the clinician fully appreciates the child's clinical presentation and the worries about the child's health. Being heard and being understood are particularly important for families who have been dismissed by the health care system. It is common for these families to have experienced distress in their efforts to obtain health care, and these adverse experiences need to be heard and acknowledged, enabling the events to be put into the past so that healing can take place.

Second, the story needs to include sufficient details about possible adverse childhood experiences (ACEs) that took place before the child's symptoms began to appear. This information is essential if the interviewer is to put together a picture-from the perspective of the child's body — of the factors that have shaped the child's stress system over time.

Third, the story needs to include sufficient details about the child's symptoms and the associated medical investigations. Only against that background can the interviewer be confident that the requisite medical assessment is complete and be in a position to think about the symptoms from a neurobiology perspective (see Chapters 4-12). In a multidisciplinary team, the clinician with a medical background is likely to be best suited to pursue this aspect of the assessment.

Fourth, using the child's body as the beacon, the interviewer needs to ask questions about the symptoms that help build a context around the symptoms: what was happening in the child's life when the symptoms arose? The process of context building is facilitated if the clinician has helped the family tell the story in temporal order, enabling the symptoms to be ordered along a time line that also marks other events in the child's and family's lives. In this context, the clinician needs to keep control of the temporal order of the interview, asking family members to put information on hold, until the correct time frame is reached in the storytelling process. Maintaining the time line is crucial in helping the family make connections - in making meaning-between events in the child's life and the child's symptoms. Most families compartmentalize and medicalize the symptoms, and fail to connect them with the distress associated with adverse life events. Through this process the story often shifts from a story of the symptoms to a story of how the child's body responded-via the symptoms - to various events in the child's and family's life stories. 
Fifth, if the child's symptoms are longer-standing rather than acute, the interviewer needs to determine how the child and family have been managing or adapting to the illness, including such matters as the attention given to the symptoms and the impact of the illness on school attendance, physical activity, and engagement with peers.

We see all of these factors at work in the following case study of Paula, the 15-year-old bed-bound girl with a four-year history of functional somatic symptoms whom we first met in Chapter 2.

\section{Case Study: Paula}

\section{Establishing a Therapeutic Relationship}

The hospital's Pain Team referred Paula to Psychological Medicine, to be assessed for admission into the Mind-Body Program run by the first author.

Paula came to the family assessment interview with her older brother and her parents. The interview took two hours and involved construction of a family genogram (including medical history across three generations), the family telling the story of Paula's development and Paula's symptoms, the formulation, and a conversation about a treatment contract for the mind-body admission.

The genogram signalled that the family constellation was uncomplicated, that there was a history of terminal cancer on both sides of the family, and that Paula and her brother were very close to the maternal grandfather, who was dying. There was also a mental health history on the mother's side of the family (see Fig. 3.1), signalling a potential risk for Paula. The interviewer noted that the illnesses of both grandfathers in a time frame that intersected with Paula's own illness would need to be woven into the family story, as would the impact of those illnesses not only on Paula but on the family. The interviewer also noted that the miscarriage that had occurred before Paula had been conceived, coupled with Paula's need to be admitted to the neonatal intensive care unit (NICU) after she was born-may have set up a dynamic in which Paula's mother was acutely sensitive about health issues that came up with Paula. 
The storytelling processing itself, as briefly summarized above, began with a question about Paula's conception. Everyone laughed and said that Paula was a very wanted baby. Paula's mother was asked briefly about the pregnancy and delivery. Paula had been a premature baby (30 weeks gestational age) and had spent one week in the NICU. On discharge from the NICU and in the first year of life, Paula had been able to regulate in terms of sleeping, feeding, and eating (breastfed for two years). She had demonstrated short-lived separation anxiety on going to preschool at three years of age.

The family gave the story clearly, and they conveyed the sense that everything had been tracking well right into primary school. As school came into focus, the interviewer suggested that Paula should now be able to access memories; progressively, and assisted when necessary by her parents and brother, Paula became the main storyteller. Paula related that she had been a physically active school-age child who enjoyed the outdoors. Although she always had some difficulties with making friends, she managed to maintain a friendship group who, like her, were interested in reading and in writing scripts for movies and plays. The interviewer then tracked Paula's health concerns by using her body as a beacon. In addition to asking detailed questions about Paula's symptoms, the interviewer made sure that the family saw how the symptoms were related to the context in which they had occurred (e.g., physical injury, illness concerns regarding the two grandfathers, and bullying).

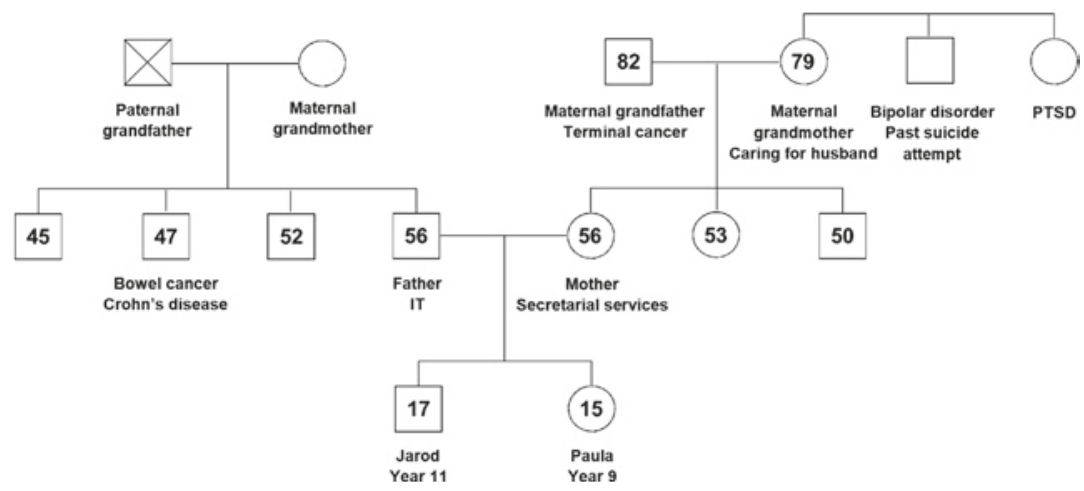

Fig. 3.1 Paula's genogram (๑ Kasia Kozlowska 2019) 
When Paula told about the fracture in the lateral epicondyle of her right femur-at 11 years of age (year 5 in school) - the interviewer commented, 'Physical injuries are a stress for the body, so the fracture was the first major stress that your body had to deal with.' When Paula teared up when her maternal grandfather's illness was mentioned, the interviewer took time to explore the impact of the illness on all members of the family. When Paula teared up again when alluding to the bullying at school, the interviewer asked her to describe the bullying in detail to make sure that everyone in the family was aware of the extent of her distress. The interviewer also asked for details about how Paula's body had responded to the bullying. At the appropriate moments in the story, the interviewer interwove questions about the death of the paternal grandfather, the deteriorating health of the maternal grandfather, and the emotional responses of the family. The emergence of multiple symptoms - limb weakness, persistent headache, intermittent abdominal pain, and musculoskeletal pain that migrated all over her body-suggested that Paula's body had not been coping with the cumulative stress. Then the interviewer tracked the family's interactions with the medical system, their increasing anxiety and confusion pertaining to the many different diagnoses given by different medical specialists (see Chapter 2 ), the efforts by Paula and the family to manage her symptoms, Paula's being bullied at school, and her increasing functional impairment. Finally, taking into account Paula's decreased exercise and her withdrawal to her bed, the interviewer tracked symptoms of autonomic dysregulation and fatigue, as well as the emergence of panic attacks.

\section{Co-constructing a Formulation}

During the assessment process the ongoing effort to consolidate the therapeutic relationship continues via the process of co-constructing the formulation. In this context, the narrative told by the child and family is framed through the lens of the stress-system model (see Chapters 4-12). What happens, in effect, is that the story told by the family (i.e., what the child and the family know) is melded together with the meaning of that story from the perspective of the body (i.e., what the clinician 
knows). The two narratives, brought together, merge into a new, shared formulation. In the case of Paula and her family, the formulation was both articulated verbally and shown visually using visual metaphors. This example shows how the clinician (KK) went about the process of weaving the family story into a formulation picking up on the issues that she (the clinician) had marked as being relevant (and that, along with many other issues, will be discussed in much more detail in Part II on the neurobiology of functional somatic symptoms).

The formulation, which incorporates material that the reader will encounter in Part II, went as follows:

Thank you all for telling us the story of the symptoms so clearly. So now let me share with you my understanding of Paula's symptoms. Even though Paula's presentation is very complex, all of Paula's symptoms reflect activation and dysregulation of the brain-body stress systems. The stress system includes all the systems in the brain and body that activate when the body senses threat and danger. The body does not distinguish between stress that is physical (like Paula's epicondyle fracture and the physical bullying that Paula experienced) and emotional stress (like the verbal bullying that Paula experienced and her distress about her maternal grandfather's illness and physical deterioration). The body responds to all types of stress with activation of the stress system. So, I am going to draw the stress system for you (circles metaphor of the stress system; see Fig. 3.2).

First, the bottom circle represents the hypothalamic-pituitary-adrenal (HPA) axis. The HPA axis activates with stress. It uses signal moleculeshormones - to communicate. The final product of activating the HPA axis is the release a stress hormone called cortisol. Cortisol is involved in energy regulation and adaptation to stress. It ensures that the body system has sufficient energy resources to deal with the stress. We know that Paula's HPA axis got switched on because activation of the HPA axis disturbs sleep. And Paula described really clearly how her sleep was disturbed both after the fracture and at the time of the bullying. Cortisol also facilitates stress responses in the brain, which we shall talk about in a bit.

The coloured circles on the left represent the autonomic nervous system - another component of the stress system (circles metaphor of the stress system; see Fig. 3.2). The autonomic system regulates body arousal on a second-by-second basis. It regulates all the organs inside the body, 


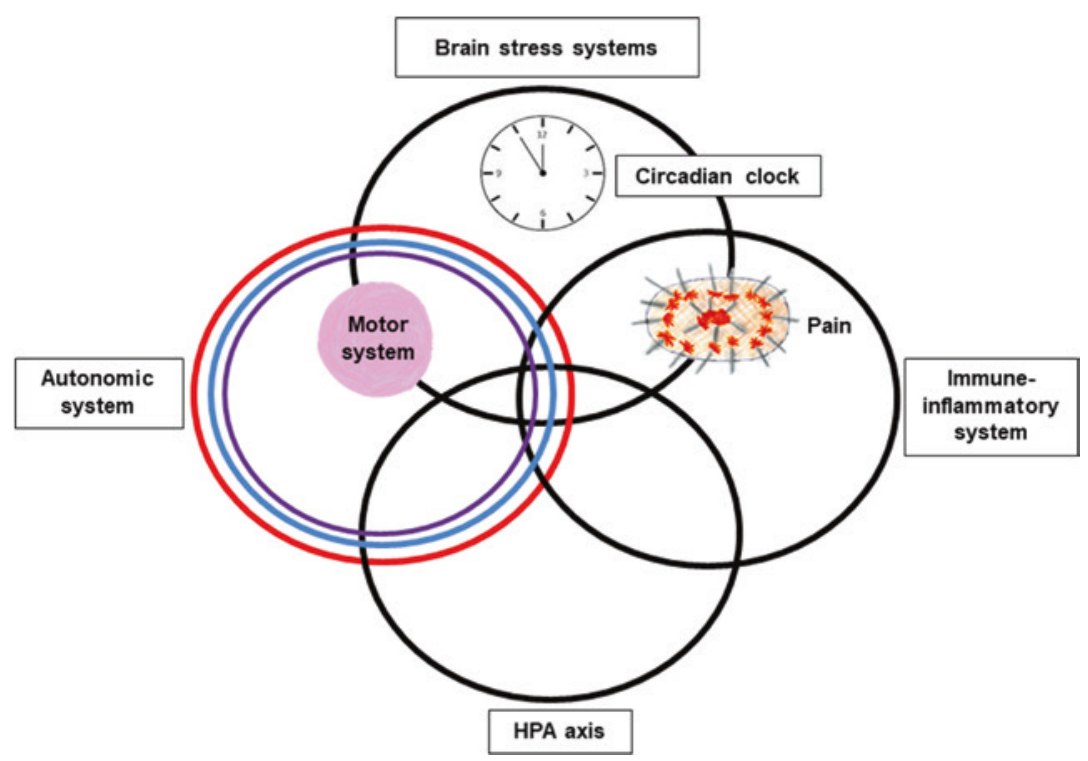

Fig. 3.2 Circles metaphor of the stress-system model for functional somatic symptoms. Online Supplement 4.4 depicts a version of the circles metaphor that can be printed out (๑ Kasia Kozlowska 2013)

including the heart. Let me show you [the interviewer draws and explains the functional diagram of the autonomic system and the symptoms associated with its activation; see Fig. 6.1]. We know that Paula's autonomic system is activated and dysregulated because the diagnosis of postural orthostatic tachycardia syndrome (POTS) (see Chapter 6) involves too little blue/restorative-parasympathetic activity (allowing heart rate to increase) and too much red/sympathetic activity (through which heart rate increases even more on standing). This is why Paula feels dizzy when standing up. And Paula's symptoms of nausea are activated by the purple/defensive parasympathetic, which switches on the gut's defensive programs, including the nausea program. The loss of regular bowel function also shows that the blue/restorative parasympathetic is not working well and that the red/sympathetic is switched on too high: the red/ sympathetic switches off the gut and can cause constipation.

Now here things get even more complicated. The red/sympathetic system works hand in hand with the motor respiratory system (part of the motor system, the pink ball in the circles metaphor of the stress system; 
see Fig. 3.2). During the interview-when Paula got teary-I counted her respiratory rate. It was 35 breaths per minute. This means that when Paula's body gets aroused-when the sympathetic system gets switched on-she also switches on the respiratory muscles, and she hyperventilates (as confirmed later on a hyperventilation challenge; see Fig. 3.3). Activation of the sympathetic system (which causes the heart to thump and the sweatiness that Paula experiences), as well as hyperventilation (which contributes to Paula's dizziness), also occurs during Paula's panic attacks. Hyperventilation contributes to dizziness because when people hyperventilate, they blow off too much carbon dioxide and lower the carbon dioxide concentration in the blood. The brain hates this. Low carbon dioxide makes the brain arteries constrict. This decreases blood flow and causes dizziness. Some people will even faint from hyperventilation.

Now we still need to talk about Paula's other symptoms: weakness in the limbs; intermittent loss of vision; chronic migrating pain; and pervasive sense of fatigue. In our diagram of the stress system, these symptoms involve the brain stress systems, which are represented by the top circle (circles metaphor of the stress system; see Fig. 3.2). Within the brain a number of regions activate in response to stress, threat, and dangerwhether the threat is physical or emotional (see Chapter 11). The stress systems in the brain also activate in response to the negative emotions such as those that emerged, for example, when Paula was being bullied or when she was thinking about her grandfather who is dying (see Chapter 12). Then we also have the brain regions that process other experiences:

- Pain maps process pain.

- Motor-processing regions process motor function.

- Sensory-processing regions process sensory function.

- Energy- and fatigue-processing regions, also known as the fatigue alarm system or fatigue alarm (and still not well defined), regulate the use of energy (including feelings that represent fatigue).

Now, the brain stress systems are supposed to switch on when the danger occurs and then to switch off once the danger has passed. However, we know from imaging studies of patients with chronic pain, functional neurological symptoms, or other functional somatic symptoms that the brain stress systems fail to switch off. What happens, instead, is that these regions become overactive and over-dominant [the interviewer draws a large red ball]. In this state, the brain stress systems can disrupt motor-processing regions and cause motor symptoms-like the weakness 


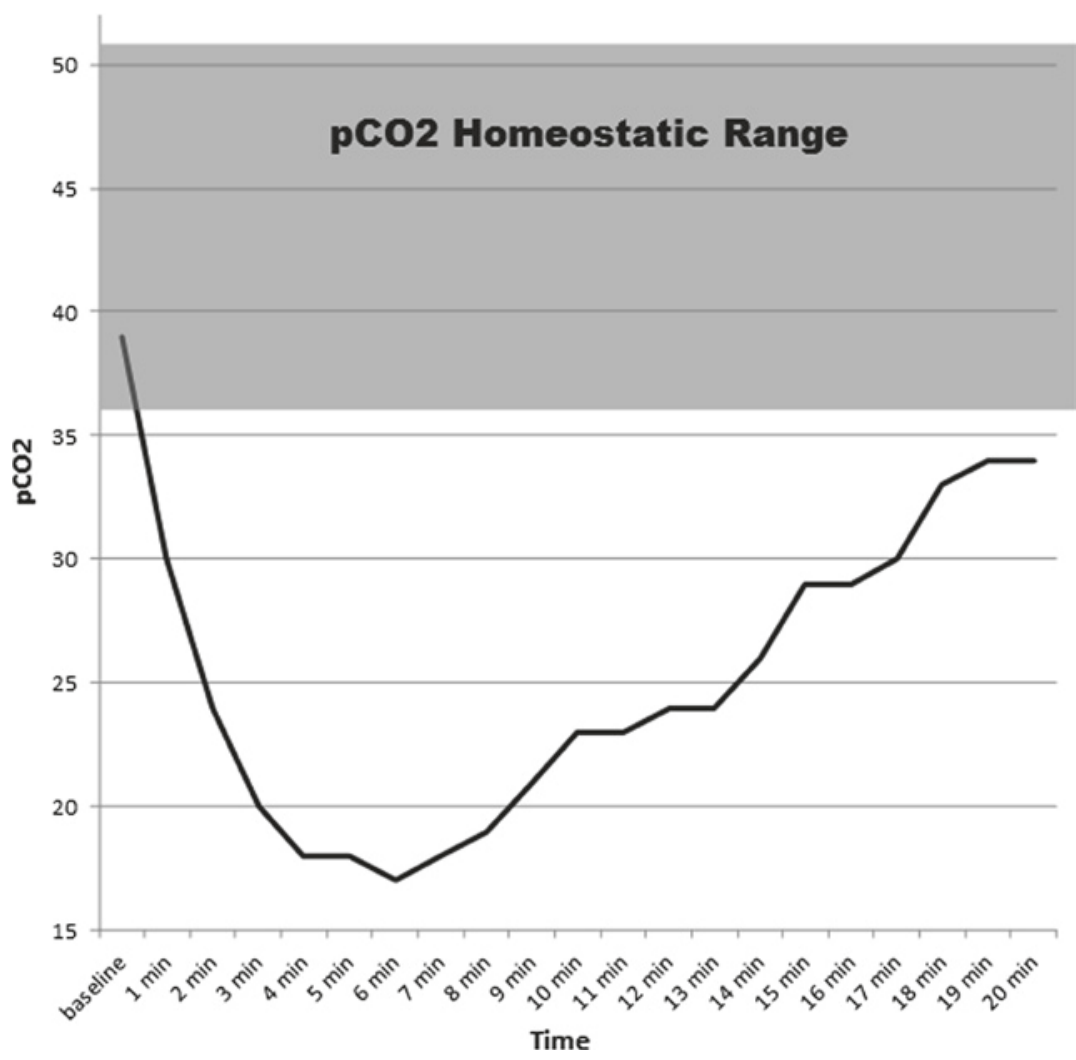

Fig. 3.3 Paula's hyperventilation challenge. This figure shows that in the resting state she was breathing at a healthy respiratory rate that kept her arterial $\mathrm{CO}_{2}$, or $\mathrm{pCO}_{2}$, within the homeostatic range. When Paula was asked to hyperventilate voluntarily, her $\mathrm{pCO}_{2}$ dropped, as it should. However, when Paula was asked to stop hyperventilating, she was unable to do so. She continued to hyperventilate, and her $\mathrm{pCO}_{2}$ did not return to baseline (the homeostatic range). The hyperventilation challenge was consistent with clinical observations that Paula hyperventilated when thinking about distressing life events, that she had trouble regulating her breathing when her system was activated as part of a panic attack, and that the poorly regulated breathing contributed to her symptoms of dizziness and fatigue (@ Kasia Kozlowska 2019)

in the legs that Paula has experienced (see Fig. 11.2). The brain stress systems can also disrupt sensory-processing regions and cause sensory symptoms-like the visual loss that Paula has experienced (see Fig. 11.3). 
And they can amplify pain by keeping the pain map switched on (see Fig. 11.5). In this way, the pain becomes chronic and can be triggered by a minor physical or emotional stress, and the pain can do odd things like migrate all over the body. That's something you all already know because you have observed the pain migrating around Paula's body. In addition, activation of the brain stress systems involves an increased use of energy, and many patients experience increased feelings of fatigue.

We are almost done. But I have forgotten to tell you about three things. This clock image represents the circadian clock (see Fig. 3.2). The circadian clock regulates the sleep cycle. When the circadian clock is dysregulated - as it is in Paula's case-it means that the brain misses out on all the restorative processes that are supposed to take place at night. Disturbed sleep also contributes to activation of the stress system-nothing is ever allowed to switch off-plus disturbed sleep increases pain. So, sorting out sleep is going to be very important.

And then, we have the immune-inflammatory system-the last component of the stress system (see Fig. 3.2). This system is very important because it contributes to chronic pain. In chronic pain this system is switched on, and immune-inflammatory cells in the body secrete pro-inflammatory substances that keep pain nerves activated, thereby signalling pain. One such cell type is the macrophage (see Fig. 9.1). Macrophages normally go around the body cleaning up debris and secreting anti-inflammatory molecules. But when they are switched into defensive mode-as happens in chronic pain — they secrete pro-inflammatory molecules that maintain pain. Exercise helps macrophages to switch into healthy restorative mode, in which they secrete anti-inflammatory molecules that decrease pain. But lack of exercise causes macrophages to switch into defensive mode. So, the fact that Paula is so deconditioned and that she is not doing any exercise is contributing to activation of the immune-inflammatory system-cells like the macrophage-and is keeping the pain maps activated. Reintroducing exercise is therefore going to be very important, too.

Finally, we come to the role of the mind. The way we use our minds can either switch on the stress system or help it settle (see Chapter 12). Paula told me that she worries about the symptoms. Sometimes she even worries that she will be sick forever. She can even visualize herself as an invalid in a wheelchair when she grows up. Every time she worries or brings up that image, she uses her mind to switch on the stress system top-down. This top-down activation of the stress system just makes things 
worse. Another factor that makes symptoms worse is attention. Every time Paula pays attention to the pain, it will intensify. Every time mum asks about the pain, watches out for it, or is experienced by Paula as worrying about it, the pain will also intensify. So, changing how we all focus our attention will be another important part of the intervention.

Now that we have finished our explanation of the stress system and its interactions with other brain regions, you can see that, although the different specialists have used different names for different symptoms, all the symptoms arise from an interrelated process: the activation and dysregulation of the stress system. [At this point the interviewer may write down the different words different specialists use and include some other words that the family is likely to run across.] Next, we are going to talk about treatment options. But before we go on, do you have any other questions?

\section{Depicting the Treatment Process via Visual Metaphor}

If the child and family accept the formulation-the story of their child's illness through the lens of the stress-system model-then the conversation moves onto treatment. The family's acceptance (or lack thereof) is usually communicated quite clearly. The tension in the room suddenly disappears. A parent may let out a sigh of relief. Faces brighten. Often someone in the family articulates their felt sense of relief: the relief that comes with understanding what is happening for the child and her body. Sometimes, if someone in the family had an aha! moment, they will share this new understanding. Sometimes the family will acknowledge that the neurobiology is very complex and thank the clinician for taking the time to explain it to them.

For some families it can be helpful to depict the process of treatment via a visual metaphor. In Figs. 3.4 and 3.5, the treatment process is represented visually using the circles metaphor and the castle-fortress metaphor, respectively. The figures depict that the clinician-and child and family-will be working together to choose interventions that will shift the child's stress system from an activated, dysregulated, incoherent state (a stress system in defensive mode) back to a more regulated, more coherent state, and to a more healthy way of functioning (a stress 


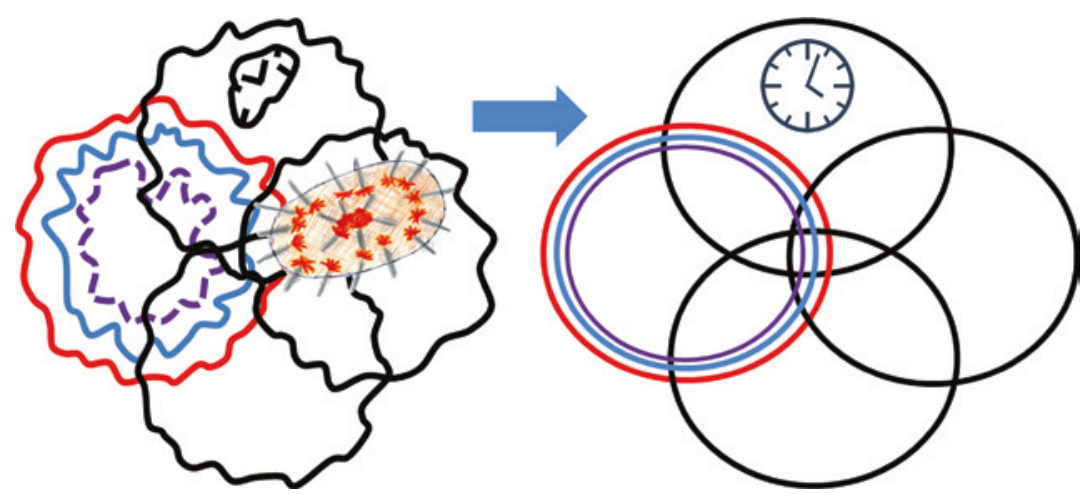

Fig. 3.4 Treatment depicted using the circles metaphor of the stress-system model for functional somatic symptoms. Using the circles metaphor, the treatment process can be conceptualized as involving a shift from a dysregulated state-with stress-system components being overactivated, underactivated, out of harmony with other components, or out of synchrony with the circadian rhythm - to a regulated state that supports health and well-being (๑) Kasia Kozlowska 2017)

\section{Castle in defensive mode}

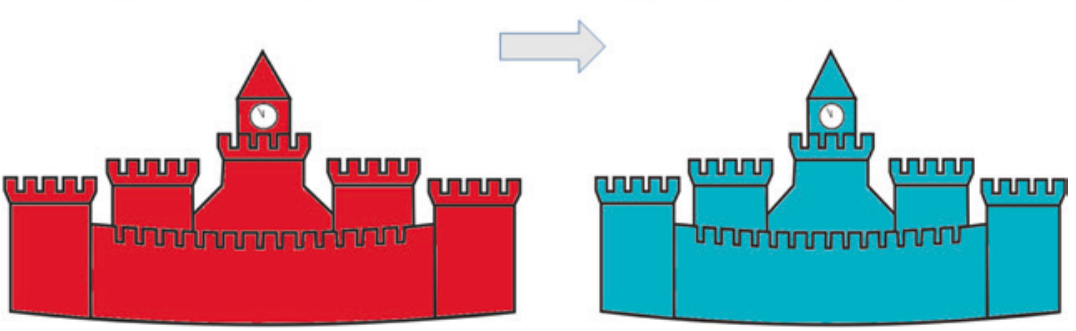

Fig. 3.5 Treatment depicted using the castle-fortress metaphor of the stress system model for functional somatic symptoms. Using the castle-fortress metaphor, the treatment process can be conceptualized as involving a shift from a castle-fortress in defensive mode (denoted by the colour red)-where battle towers are manned to protect the castle-fortress from attack-to a castle-fortress in peace time (denoted by the colour blue) (๔ Kasia Kozlowska 2017) 
system in restorative mode). The stress system in defensive mode supports the generation of functional somatic symptoms, whereas a stress system in restorative mode supports health and well-being and is not compatible with the generation of functional somatic symptoms.

If specific factors have been identified as contributing to stress-system activation, these can be written in above the visual representation, with large arrows that depict their role in activating the stress system. For example, in Paula's case, bullying at school, worry about the deterioration of her maternal grandfather, ruminating and catastrophizing about school, and parental attention to the symptoms would all be written into the visual representation, highlighting the role of these factors in activating Paula's stress system.

\section{Rationale for the Interventions That Make Up Treatment}

The conversation then moves onto the rationale for using certain interventions in the treatment program. The treatment rationale builds directly on the neurobiology of the stress system, as previously discussed with the family. Sometimes, the rationale for certain interventions has already been addressed during the formulation itself, as when we discussed with Paula the need for her to start mobilizing again. In offering Paula an admission into our inpatient program, we also explained the various other interventions that would be implemented as part of the program. The conversation went as follows:

Now let's talk about treatment-what needs to happen for Paula to get well. As you know, the Pain Team are really keen that Paula is given a place in our Mind-Body Program. And we are happy to offer Paula two weeks in the program. But let us tell you about the program so that Paula can decide if it is something she wants to do. [The program is described in detail by a member of the team.] Paula will come into the adolescent medicine ward for two weeks to learn the program. After completing those two weeks, she will then need to take the program home and continue it, with the support of the family, for the next 12 months, or even longer. She will need to build some components of the program-for example, the regulation strategies and the regular exercise-into her life for the long term. 
Earlier, when we discussed the neurobiology of Paula's symptoms, we saw that they all involve the activation and dysregulation of the stress system. Treatment of functional somatic symptoms - using body-mind interventions-aims to help Paula switch off the stress system and to regulate the stress system better. Because Paula has been sick such a long time, we shall use every intervention and strategy we know-at the same time- to help her stress system regulate better. Here is the plan that I have in my mind:

- Right after admission, we shall do a blood test to check Paula's iron level, vitamin B12, vitamin D, and a few other things that weren't checked before. We shall also perform a hyperventilation challenge to see how significant Paula's hyperventilation is and how well she is able regulate her breathing. Paula will also do a standing test for the POTS, so we can see how her body regulates heart rate and blood pressure when she stands up from a lying-down position on waking up in the morning. We always make sure that the medical assessment is complete and that all the boxes are ticked. [This final set of tests found that Paula was iron deficient-ferritin level $4 \mu \mathrm{g} / \mathrm{L}$ (reference range $10-150 \mu \mathrm{g} / \mathrm{L}$ ). This iron deficiency contributed to her fatigue. The hyperventilation challenge confirmed Paula's hyperventilation (see Fig. 3.3). The standing test for POTS revealed that the autonomic dysregulation was severe and needed active treatment to stabilize (see Table 3.1). Paula's standing test showed (1) a minimum heart rate increase of 38 beats per minute, and a maximum increase of 64 beats per minute, on standing, and (2) no substantial change in blood pressure within ten minutes. In children, an increase in heart rate of $>40$ beats per minute is consistent with orthostatic intolerance.]

- Our first immediate intervention will be to stabilize Paula's sleep-the circadian clock-to harness all the restorative processes that take place at night. Good sleep will help Paula's body regulate. No one can regulate without good sleep. Paula can start the sleep intervention at home while she is waiting for a bed in the Mind-Body Program. You need to put together a timetable that marks bedtime and getting up time. Paula will need to go to bed at the same time every day and also get up at the same time. She will need to sit in the sun in the morningon waking up-for about an hour. We shall also use melatonin - the natural substance that the brain secretes-to help regulate her sleep. If these measures are not sufficient, there are other things we can do (see Chapter 5). [In the end, Paula's sleep was regulated with $9 \mathrm{mg}$ melatonin and $25 \mathrm{mg}$ quetiapine.] 
Table 3.1 Paula's heart rate and blood pressure values on the Standing Orthostatic Tolerance Test (@ Kasia Kozlowska 2019)

\begin{tabular}{lll}
\hline Time period & Blood pressure & Heart rate \\
\hline Baseline (lying down) & $117 / 68$ & 84 \\
1 minute (standing) & $124 / 80$ & 135 \\
2 minutes (standing) & $132 / 85$ & 128 \\
3 minutes (standing) & $132 / 86$ & 128 \\
4 minutes (standing) & $127 / 82$ & 132 \\
5 minutes (standing) & $112 / 79$ & 122 \\
6 minutes (standing) & $111 / 87$ & 146 \\
7 minutes (standing) & $124 / 85$ & 128 \\
8 minutes (standing) & $93 / 66$ & 126 \\
9 minutes (standing) & $115 / 90$ & 126 \\
10 minutes (standing) & $121 / 88$ & 126 \\
\hline
\end{tabular}

- Our second intervention during the admission will be to treat the POTS (the dysregulation of the autonomic system) with body strategies: increasing fluid intake, taking salt tablets, using stockings, and implementing slow-breathing strategies that help increase blue/parasympathetic function and decrease red/sympathetic function [point out the relevant nerves on Fig. 6.1]. If these strategies are not enough, there are other things we can do (e.g., treatment with propranolol) (van der Zalm et al. 2019). The treatment should help Paula's symptoms of dizziness on standing and, over time, her energy levels. [In the end, treatment for POTS included salt tablets, increased water intake, and pressure stockings; the slow-breathing strategies were incorporated into the broader strategy for improving Paula's capacity for self-regulation (see next item).]

- Paula will work with [name of psychologist] to work out what mind-body strategies she is able to use to help regulate her body and her stress system. [In the end, Paula's key bottom-up strategies were slow breathing, muscle relaxation, and shifting attention away from pain to sensations that were pleasant.]

- Paula will also need to work with [name of psychologist] to determine how she contributes to the symptoms with her mind, as by worrying, ruminating, catastrophizing, and so on. [Basic cognitive-behavioural interventions were used to address these issues and, in combination with mindfulness interventions, were continued with a psychologist after discharge.] 
- During the first week of the admission—as we get to know Paula better-we shall also decide if Paula will need medication (a selective serotonin reuptake inhibitor [SSRI]) to treat her severe anxiety, or whether mind-body strategies will be sufficient. We are raising the potential need for medication now because Paula is very ill and because we know - from the information about Paula's panic attacks - that her anxiety is quite severe. You also need to know that anti-anxiety medication can be helpful in treating POTS (Rowe 2014). [We found that Paula's anxiety was overwhelming and completely incapacitating. Alongside mind-body strategies, she was treated with fluoxetine $20 \mathrm{mg}$ (increased slowly from $2.5 \mathrm{mg}$ in the morning, in $2.5 \mathrm{mg}$ increments) and quetiapine $6.25 \mathrm{mg}$ in the morning, which helped take the edge of her anxiety and helped her get to the hospital school.]

- Paula will work with the physiotherapist on a daily basis to set up an exercise program that she can take home. The exercise will help the POTS, anxiety, and deconditioning, and it will help shift Paula's macrophages into restorative mode - which, in the long term, will help decrease Paula's pain. [Paula continued an exercise program that was monitored by an external physiotherapist and that her parents also continued to oversee.]

- Paula will go to the hospital school every morning. During the afternoon, she can either attend school or the adolescent group-whichever she prefers. She can use the school to practice her strategies for the pain and fatigue, and to build up her energy levels, enabling her to resume attending her own local school. [Paula returned to her own school, full time, on discharge.]

- There is no visiting during the day, when Paula is busy with the program. Visiting hours are limited to the hours after she has completed that day's program. There is no program on the weekend; Paula will have a gate pass from hospital to go home for Saturday night. Because attention to symptoms makes the symptoms worse, we ask the family, when together with Paula, to practice not asking about symptoms but to ask about what Paula did that day (if in the hospital) or to engage in some other activities. Paula is also to practice not talking about the symptoms. She can, however, boast to everyone about what she is doing to manage the symptoms.

- We will have a weekly family meeting to track how Paula is doing and to begin the process of helping everyone in the family make the necessary changes that will support Paula's health and well-being in the long term. 
- We expect that at some point during the admission, Paula might have some difficult days-might feel exhausted and unable to go on. If that happens, we shall use it as opportunity for the family to see how Paula (and they) will manage days that are difficult and that feel like a setback. [Paula's temporary setback came after she jarred her arm while travelling on a bus with her father while returning home from a Saturday night concert. The bus had stopped suddenly, activating high-intensity back pain and panic attacks, and Paula wanted to retreat to bed. While recovering from this setback, Paula was encouraged to use her various strategies (as described above) with increased frequency, and she attended the hospital school in a wheelchair, soon graduating to pushing it herself. Within a few days, she returned to the point of progress where she had been a few days earlier. The episode also functioned as a trial run for Paula's mother-a coaching exercise- as to what she needed to do when Paula had a setback at home.]

- Finally, Paula's present diet is low in fruit, vegetables, yogurt, and meat. So, Paula needs to start improving her diet while she is waiting for the hospital admission. A healthy diet has to be part of any program for getting well. [The family also opted to incorporate probiotics into Paula's daily intake.]

\section{Therapeutic Contract}

After the treatment has been discussed, a therapeutic contract needs to be agreed, including the following: confirmation that the child wants to come into the Mind-Body Program and that the parents consent to all components of the program; the goals that the child has to meet before the admission itself; the time frame of the admission; the program structure; and discussion and negotiation of any potentially 'sticky' points. The contract also involves discussion as to what will happen with outpatient treatment afterward-for example, with referral or handover back to local services. At this time of negotiating a therapeutic contract, the family has the option of deciding whether they want to take up the offer of inpatient treatment or, instead, whether they would like the team to help them set up a program with resources from their local community. The team also has the option of withdrawing the offer of an inpatient admission if the family do not agree to core components 
of the treatment program or if the child or family are not sufficiently motivated. In the latter situation, the offer of the program-with its specific, defined conditions-remains open to the child and family in the future.

Occasionally, we admit a child into our Mind-Body Program with only the parents' consent (and contract) - even if the child does not want to come into the program. This is sometimes necessary because the child, due to severe anxiety, will not cooperate with any aspect of treatment or because the lack of cooperation is part of the presenting picture. In this scenario the intervention begins by establishing a therapeutic environment in which the child is given multiple opportunities to engage with different therapists within the program-the nursing staff, psychotherapist, physiotherapist, and school staff-on a daily basis. In these scenarios, the child is, if necessary, taken to the school classroom on her bed.

\section{The Outcome of the Mind-Body Admission for Paula}

The overall treatment program involved both a preadmission intervention-Paula had to reach some goals before admission into the hospital program-and a two-week admission to the Mind-Body Program itself, which was extended to three weeks because of Paula's significant level of deconditioning (since she had been sick for so long). The interventions implemented prior to admission included the following: re-establishing a normal sleep-wake cycle, along with an hour of sun exposure immediately after arising; establishing a healthy diet, with regular meals; and establishing an exercise routine as part of the process of gradual reconditioning (initially, for example, by implementing short walks outside the house to the front gate of the garden). The interventions implemented during her program are those that were discussed with the family above. After completion of the hospital program, Paula took the program home with her and continued to implement it with the help of her parents, a psychologist, a local physiotherapist, and her general practitioner. Her pain and fatigue resolved to a large extent; her anxiety continued to be challenging to manage; and she had a number of 
time-limited relapses of functional neurological symptoms (leg weakness and vision loss). But she continued to persevere with the program and to attend school — and stay connected to her friendship group-just as she had done in the hospital setting.

In this chapter we have examined how multidisciplinary teams engage with children with functional somatic symptoms and their parents through the therapeutic process of a family assessment interview. As we have seen through our discussion of Paula, the assessment interview serves multiple purposes. Among other things, it assists the family in telling the story of the symptoms in relation to the broader story of the events and challenges that occurred in the life of the child and family; it facilitates a shared understanding of those events and challenges; it enables the co-construction of a formulation by looking at the information provided by the family through the lens of the stress-system model; it provides a rationale for treatment; and it facilitates the articulation of a therapeutic contract through which everyone agrees to work together before, during, and after the period of the mind-body intervention. We hope that clinicians working in a broad range of clinical settings will be able to adapt some of the ideas presented in this chapter to their own way of working and to the needs of their own clinical contexts and practice

\section{References}

Kozlowska, K., English, M., \& Savage, B. (2013). Connecting Body and Mind: The First Interview with Somatizing Patients and Their Families. Clinical Child Psychology and Psychiatry, 18, 223-245.

McGoldrick, M., Gerson, R., \& Petry, S. (2008). Genograms: Assessment and Intervention. New York: Norton.

Rowe, P. C. (2014). General Information Brochure on Orthostatic Intolerance and Its Treatment. Baltimore, MD: Chronic Fatigue Clinic, Johns Hopkins Children's Center. http://www.dysautonomiainternational.org/pdf/ RoweOIsummary.pdf. 
Sattler, J. M. (1992). Assessment of Children. San Diego, CA: Jerome M Sattler, Publisher.

Van Der Zalm, T., Alsma, J., Van De Poll, S. W. E., Wessels, M. W., Riksen, N. P., \& Versmissen, J. (2019). Postural Orthostatic Tachycardia Syndrome (POTS): A Common but Unfamiliar Syndrome. Netherlands Journal of Medicine, 77, 3-9.

Worsely, C., Whitehead, K., Kandler, R., \& Reuber, M. (2011). Illness Perceptions of Health Care Workers in Relation to Epileptic and Psychogenic Nonepileptic Seizures. Epilepsy \& Behavior, 20, 668-673.

Open Access This chapter is licensed under the terms of the Creative Commons Attribution-NonCommercial-NoDerivatives 4.0 International License (http://creativecommons.org/licenses/by-nc-nd/4.0/), which permits any noncommercial use, sharing, distribution and reproduction in any medium or format, as long as you give appropriate credit to the original author(s) and the source, provide a link to the Creative Commons license and indicate if you modified the licensed material. You do not have permission under this license to share adapted material derived from this chapter or parts of it.

The images or other third party material in this chapter are included in the chapter's Creative Commons license, unless indicated otherwise in a credit line to the material. If material is not included in the chapter's Creative Commons license and your intended use is not permitted by statutory regulation or exceeds the permitted use, you will need to obtain permission directly from the copyright holder.

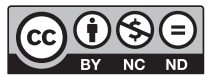

